\title{
EXPERIMENTAL INVESTIGATION ON TENSILE AND FLEXURAL PROPERTIES OF KENAF/PINEAPPLE HYBRID NATURAL FIBER COMPOSITES
}

\author{
K.Rajendran ${ }^{1}$, N.Venkatesan ${ }^{2}$ \\ ${ }^{I}$ PG Student, Mechanical Engineering, Tagore Engineering College, Chennai-600127 \\ ${ }^{2}$ Associate Professor, Mechanical Engineering, Tagore Engineering College, Chennai-600127
}

\begin{abstract}
The natural fiber composite fabrication has been a highly preferred field of research due to its unique properties like low mass density, stiffness, light in weight, low budget, easy obtainability and exceptional mechanical properties. These properties had found many applications in aircraft, space, automotive, sporting goods etc. The natural hybrid composites are the centre of attention for researchers as it serves in various engineering applications as asubstitute to commonly used synthetic fiber composites. The motive of this project is to study and enquire the tensile and flexural properties of Kenaf/Pineapple natural hybrid fiber with reinforced epoxy resin experimentally. The mechanical properties of Kenaf fiber are enhanced by incorporating the kenaf fiber with pineapple fiber. These hybridisations of fibres are made at different weight fractions and are incorporated with the mixture of resin epoxy LY556 and hardener HY951 by hand layup techniques. ASTM (American Society for Testing and Materials) standards were strictly followed for the preparation and testing of the tensile and flexural test specimens.
\end{abstract}

Keywords: Composite, Kenaf fiber, Pineapple fiber, tensile properties, epoxy resin.

\section{INTRODUCTION}

Composites are flexible and practical materials that can be a solution to problems of various applications with a possibility of introducing new properties to the materials. Nowadays, there is a booming involvement in discovering new applications of natural fiber reinforced composites. Natural fibers seem to be the best materials which come as the feasible and suitable replacement for non renewable synthetic fiber. Natural fibers are highly preferred for use in composite materials since it has characteristics such as light in weight, less cost, high specific strength, high specific modulus, easy and safe to handle, eco-friendly, availability, easy to make, non-toxic nature. Natural composite fibers are studied mainly due to its eco-friendly character and unique properties such as ease of separation, improved energy recovery, carbon dioxide neutrality, ease of recycling.

Among the available natural fibers, Pineapple leaf fibers (PALF) possess exceptional mechanical properties. The leaves of the plant Ananus cosmosare the source of the PALF. They are composed of cellulose (70-82\%), lignin $(5-12 \%)$ and ash $(1.1 \%)$. The high cellulose content with comparatively low micro-fibrillar angle of PALF is the major reasons for the exceptional mechanical properties of the fibers.

Another natural fiber, Kenaf performs relatively better among the rice straw fiber, bagasse, stramineous fiber, cocos fiber, hemp, flax, banana, cotton, coir, sisal, etc., due to the inexpensive and commercial availability of the fiber in a required form. Kenaf grows in warm season and it is used to make cordages, twine and sackcloth.Commonly used synthetic fibers can be replaced with the kenaf fibers in various applications, kenaf grows at a quicker rate compared to other natural fibers. The kenaf consists of 35$40 \%$ bast fiber and $60-65 \%$ core fibers by weight of the kenaf's stalk. Kenaf contains approximately $65.7 \%$ cellulose, $21.6 \%$ lignin and pectin and other composition. Therefore, kenaf composites may shows excellent mechanical properties and could be a best possible solution for wood substitution.

Many researches and studies have been conducted to study the mechanical, thermal and physical characteristics of kenaf and pineapple fiber reinforced composites. Different matrix materials were used in different research. Among the various researches, the normally used matrixes are polyester resin, natural rubber, polypropylene, polyethylene, polycarbonate, epoxy resin, phenol formaldehyde.

It has been determined that the different property of kenaf and pineapple composites varies randomly; and it depends mainly on environmental origin of fibers, growth atmosphere and processing methods.

In this study, the kenaf and pineapple fiber composites reinforced with polyester resin have been examined experimentally and the mechanical properties such as the tensile strength, flexural strength, stress-strain relations were evaluated. 


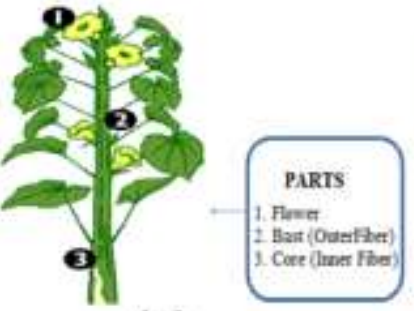

$\left(a_{1}\right)$

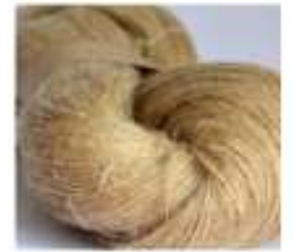

$\left(a_{3}\right)$

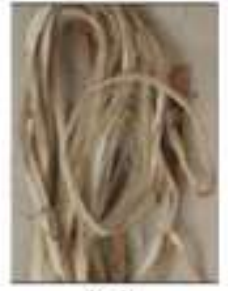

$\left(\mathrm{a}_{2}\right)$

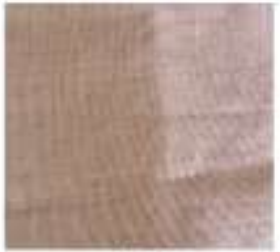

$\left(a_{4}\right)$
Figure 1. $\left(a_{1}\right)$ Kenaf Plant, $\left(a_{2}\right)$ Kenaf Fiber, (a) Kenaf Yam, $\left(a_{4}\right)$ Kenaf Fabric.

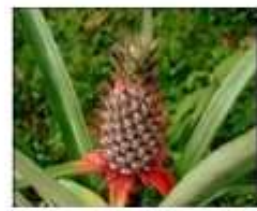

$\left(b_{1}\right)$

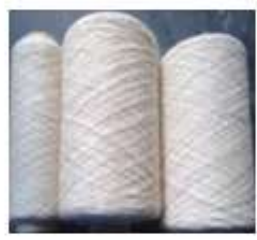

$\left(b_{3}\right)$

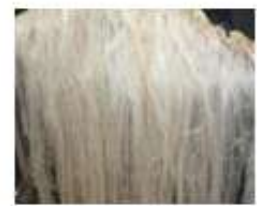

$\left(b_{2}\right)$

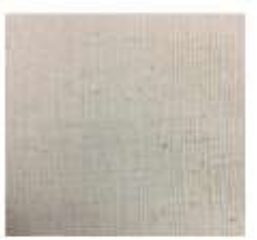

$\left(b_{4}\right)$
Figure 2. $\left(b_{1}\right)$. Pineapple Plant, $\left(b_{2}\right)$. Pineapple Fiber, $\left(b_{3}\right)$. Pineapple Yam, $\left(b_{4}\right)$. Pineapple Fabric

\section{MATERIALS}

\subsection{Fibers}

Kenaf fiber is extracted from the stem part of Kenaf plant from the family Hibiscus cannabinus. Pineapple is lignocelluloses and multi-cellular material extracted from the leaf of plant Ananas cosomus of the family Bromeliaceous. The fiber is extracted by hand scraping after beating the leaves to break up the pulpy tissue. But here the fibers are purchased as bi-directional mat form.

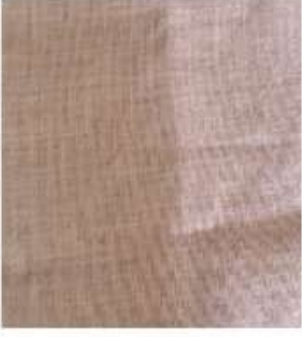

Kenaf Fiber Mat

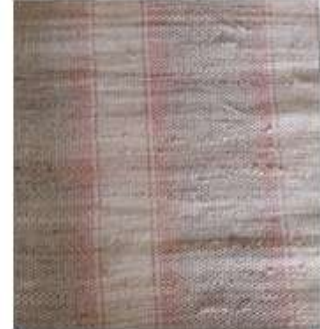

Pineapple Fiber Mat
Fig 3: Fibers as Mat/Fabric form

\subsection{Extraction of Fibers}

The obtained fibers are cleaned with water and dried. Then the fibers are parted with hands patiently. Pineapple and Kenaf fibers are drenched in water and then crushed with a hammer. And finally, the fibers are removed out from the husks and comb. After drying the fibers under the normal room temperature, the fibers are parted further into individual states by combing the fibers with cotton carding frame for several times. Then weight and length of the fibers are measured.

\subsection{Weight Fraction of the Fiber}

The specific weight fraction of fibers was determined by evaluating the weight of the matrix taken. The matrix's weight was estimated by multiplying the density and volume of the matrix taken. In case of the hybrid combination, the specific weight fraction of fibers is shared between the kenaf and pineapple fibers.

\subsection{Preparation of Epoxy and Hardener}

The composite plates were prepared using a combination of epoxy LY556 and hardener HY951 at a weight ratio of 10:1. This mixture possesses a viscosity of $10-20$ poise at a temperature of $25^{\circ} \mathrm{C}$.

\subsection{Mould Preparation}

Mould made of synthetic rubber of dimensions 300mm x $300 \mathrm{~mm} \times 4 \mathrm{~mm}$ with four beadings is prepared. Hand layup method is employed throughout the preparation. The fiber mats are made at a size of $300 \mathrm{~mm} \times 300 \mathrm{~mm}$ dimensions. The upper and lower surfaces of the mould and the side walls are layered with remover and are let to dry. During the curing process, the outer surfaces are covered with glass plates to compress the fibers from top and bottom to keep out the waste materials from entering the composites.

\section{MANUFACTRUING METHOD}

\subsection{Hand Layup Technique}

Firstly, the pineapple and kenaffiber fabrics were cut into the required size of $300 \mathrm{~mm} \times 300 \mathrm{~mm}$. The suitable numbers of fiber fabrics were taken as two or more. Then the fibers 
were weighted and accordingly the resin epoxy LY556 and hardener HY951 were weighted and mixed in a weight ratio of 10:1. Necessary steps were made to avoid the formation of air bubbles in the matrix, because the air bubbles may cause failure in the material. A releasing film and a polymer covering were applied to the sheets. After it was covered with a fiber plies and rolled using cylindrical rod as shown in Fig. 4. In the same manner, the required numbers of fiber layers were added to the composites. Finally, the composites are cured and hardened for a period of 48 hours. Hence the composite plates of size $300 \mathrm{~mm} \times 300 \mathrm{~mm} \times 4 \mathrm{~mm}$ were prepared as shown in Fig.5 (a) and Fig. 5 (b).

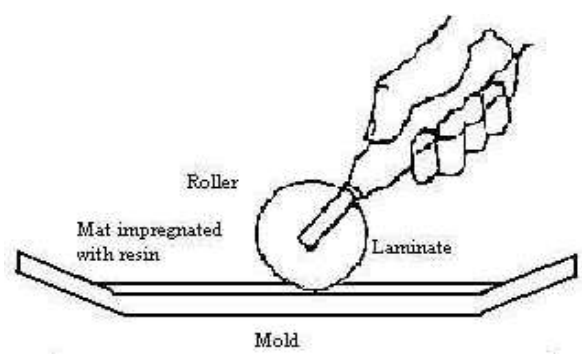

Fig 4: Hand Layup Technique

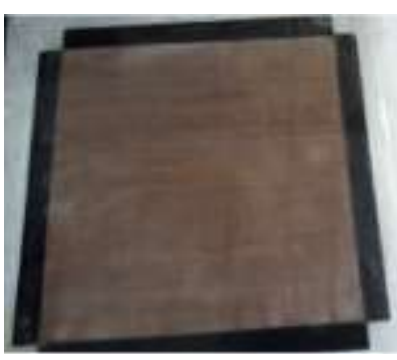

(a)

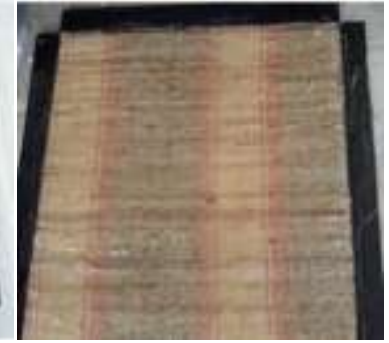

(b)
Fig 5: (a) Pure Kenaf fiber Composites Plate, (b). Kenaf/Pineapple fiber hybrid Composite Plate.

\subsection{Tensile Test Specimen Sampling}

Tensile test specimens are cutted with proper dimensions from prepared composites plates as per ASTM D638 standards as shown in fig 6. Thicknesses of samples were evaluated by calculating the average of three readings measured at different points along the sample. Different samples are as mentioned in table 1 and shown in fig 7.

Table 1: Sample Identification

\begin{tabular}{|c|c|}
\hline Sample Types & Identifications \\
\hline $\begin{array}{l}\text { Pure Kenaf fiber Composites } \\
(4.12 \mathrm{~mm} \text { thickness })\end{array}$ & 1TA, 1TB \\
\hline $\begin{array}{l}\text { Kenaf/Pineapple fiber Hybrid } \\
\text { Composites }(4.12 \mathrm{~mm} \text { thickness }\end{array}$ & 2TA, 2TB \\
\hline
\end{tabular}

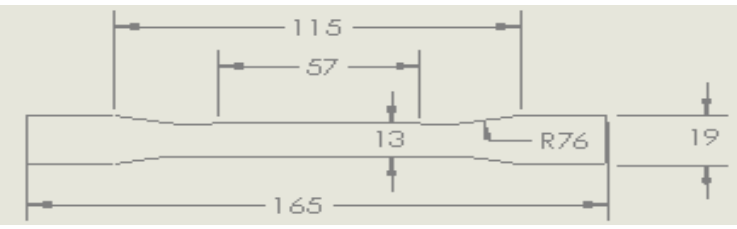

Fig 6: Tensile Test Specimen Diagram as per ASTM D638

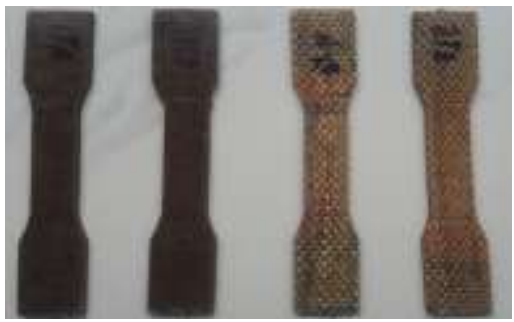

Fig 7: Tensile test specimen

\subsection{Graphs}

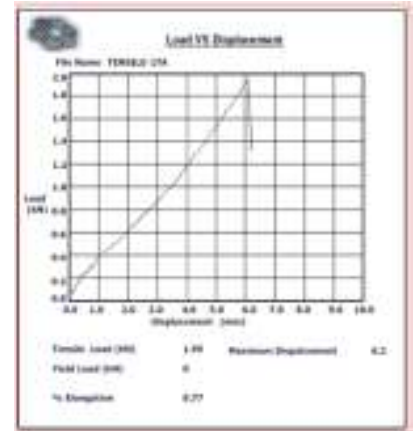

(a)

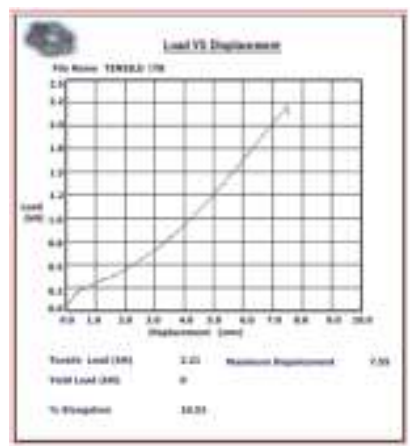

(c)

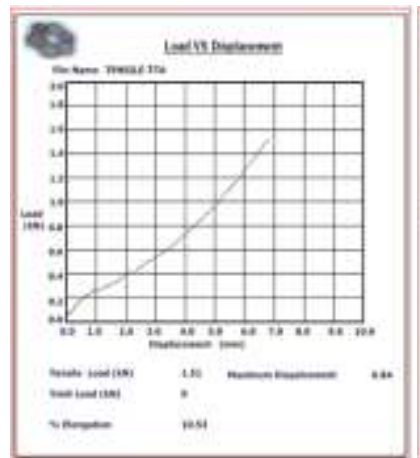

(e)

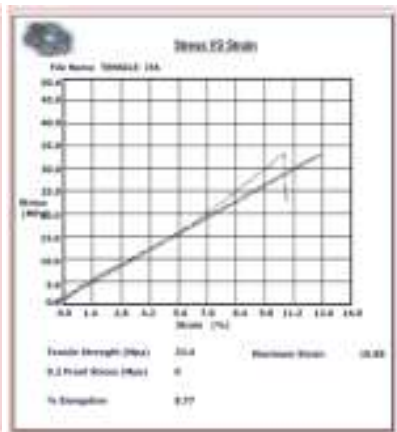

(b)

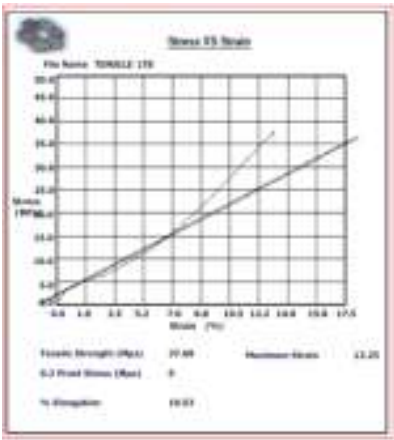

(d)

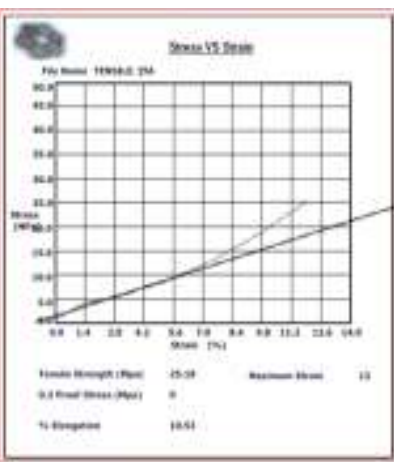

(f) 


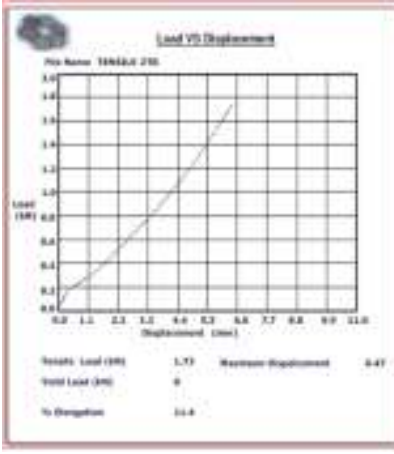

(g)

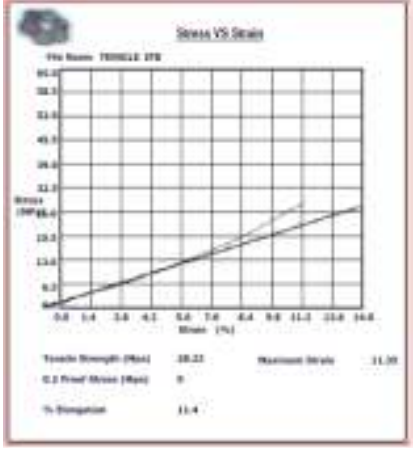

(h)
Fig 8: (a, c, e, g) Load vs Displacement, (b. d, f, h) Stress vs Strain

\subsection{Flexural Test}

Flexural test specimens (2 pieces from each plate) are cutted with proper dimensions from prepared composites plates as per ASTM D790 standards. Thicknesses of samples were evaluated. The thickness for each specimen was calculated by averaging the thicknesses measured at different points of the specimens. Different samples are identified as mentioned table2.

Table 2: Sample Identification

\begin{tabular}{|l|l|}
\hline Sample Types & Identifications \\
\hline $\begin{array}{l}\text { Pure Kenaf fiber composites (4.12 } \\
\text { mm thickness) }\end{array}$ & 1FA, 1FB \\
$\begin{array}{l}\text { Kenaf/Pineapple fiber hybrid } \\
\text { composites (4.12 mm thickness) }\end{array}$ & 2FA, 2FB \\
\hline
\end{tabular}

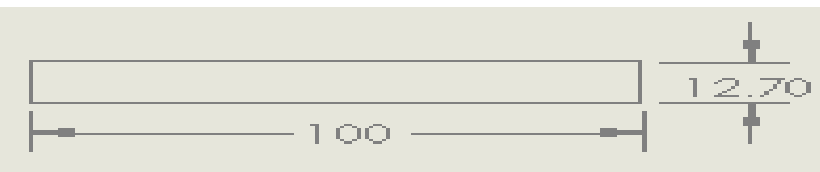

FLEXURAL TEST

Fig 9: Flexural Test Specimen Diagram as per ASTM D790

\section{Flexural Test Graphs}

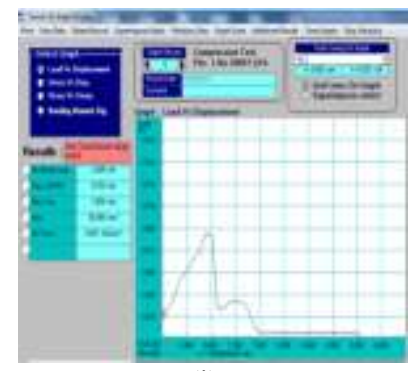

(i)

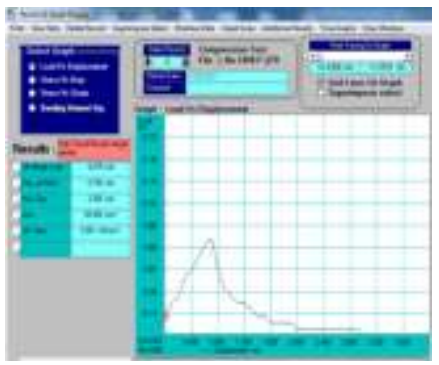

(ii)

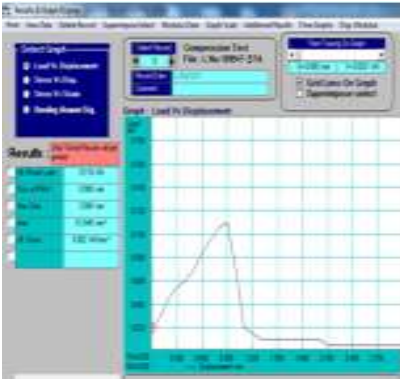

(iii)

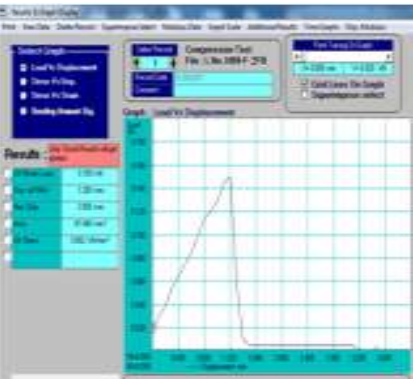

(iv)
Fig 10: Flexural Test (i, ii, iii, iv) - Load vsDisplacement

\section{RESULTS AND DISCUSSION}

\subsection{Mechanical Properties}

\subsubsection{Tensile Strength}

Fig.11shows the comparison of tensile strength of kenaf and pineapple fiber reinforced composite specimens in $\mathrm{MPa}$. It is clear from the fig.7 (a to $\mathrm{h}$ ) the tensile strength is increasing for both kenaf and pineapple fiber reinforced composites. Regarding kenaf composite, the tensile strength of sample 1B was increased which compared to the sample 1A (from fig.11).

The fig.11 also concludes that the kenaf fibers composite's tensile strength is higher than the hybrid kenaf/pineapple fiber composite. It is made evident that composite strength mainly depends on fiber loading, fiber strength and interfacial strength between fiber and matrix. Tensile properties of composite give some indirect information about interfacial bonding between fiber and matrix. In average, the result of pure kenaf fiber tensile strength was high.

\subsubsection{Flexural Test}

It is clear from the fig.9 (i to iv) that the flexural strength is increasing for kenaf and pineapple fiber reinforced composites. Regarding pineapple/kenaf hybrid composite from fig.13, the flexural strength of sample $2 \mathrm{FB}$ was high when compared to the sample 2 FA. In average, the result of hybridised kenaf/pineapple flexural value was high.

\subsubsection{ValueComparison}

Table 3: Tensile Strength value comparison

\begin{tabular}{|c|c|c|c|c|}
\hline \multirow{2}{*}{$\begin{array}{l}\text { Specimen } \\
\text { ID }\end{array}$} & \multirow{2}{*}{$\begin{array}{l}\text { Specimen } \\
\text { Details }\end{array}$} & \multicolumn{3}{|c|}{ Tensile Strength } \\
\hline & & $\begin{array}{l}\text { T-A } \\
(\mathrm{Mpa})\end{array}$ & $\begin{array}{l}\text { T-B } \\
(\mathrm{Mpa})\end{array}$ & $\begin{array}{l}\text { Avg } \\
\text { (Mpa) }\end{array}$ \\
\hline 1 & $\begin{array}{ll}\text { Pure } & \text { Kenaf } \\
(0 / 40) & \end{array}$ & 33.40 & 37.68 & 35.54 \\
\hline 2 & $\begin{array}{l}\text { Hybrid } \\
\text { Pineapple/Kenaf } \\
(20 / 20) \\
\end{array}$ & 25.18 & 28.23 & 26.70 \\
\hline $\begin{array}{l}\text { Best } \\
\text { Result }\end{array}$ & \multicolumn{3}{|c|}{ Pure Kenaf Composites } & 35.54 \\
\hline
\end{tabular}


Table 4: Flexural Strength value comparison

\begin{tabular}{|l|l|l|l|l|}
\hline \multirow{2}{*}{$\begin{array}{l}\text { Specimen } \\
\text { ID }\end{array}$} & $\begin{array}{l}\text { Specimen } \\
\text { Details }\end{array}$ & $\begin{array}{l}\text { F-A } \\
(\mathrm{KN})\end{array}$ & $\begin{array}{l}\text { F-B } \\
(\mathrm{KN})\end{array}$ & $\begin{array}{l}\text { Avg } \\
(\mathrm{KN})\end{array}$ \\
\cline { 3 - 5 } & $\begin{array}{l}\text { Pure Kenaf } \\
(0 / 40)\end{array}$ & 0.085 & 0.075 & 0.08 \\
\hline 2 & $\begin{array}{l}\text { Hybrid } \\
\text { Pineapple/Kenaf } \\
(20 / 20)\end{array}$ & 0.110 & 0.150 & 0.13 \\
\hline $\begin{array}{l}\mid \\
\text { Best } \\
\text { Result }\end{array}$ & \multicolumn{3}{|l|}{ Hybrid Pineapple/Kenaf } & 0.13 \\
\hline
\end{tabular}

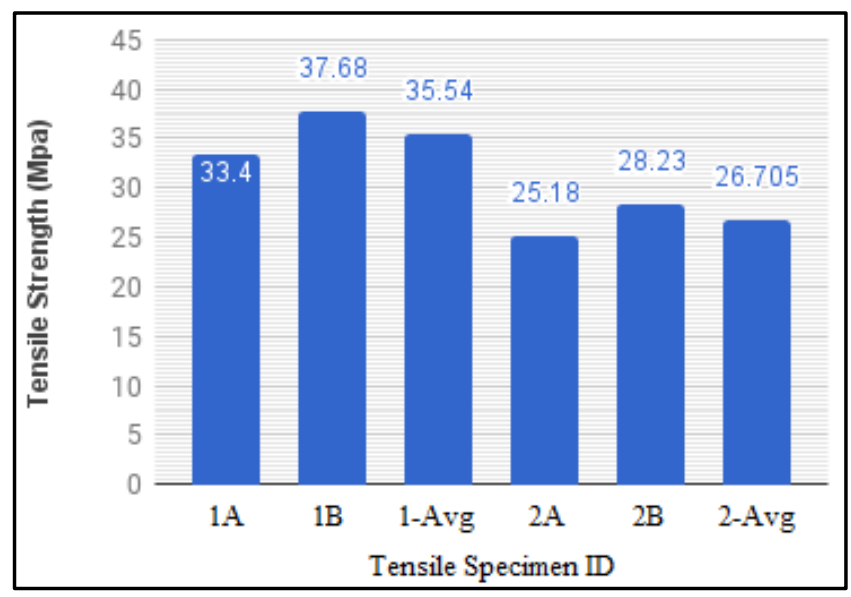

Fig 11: Tensile Strength

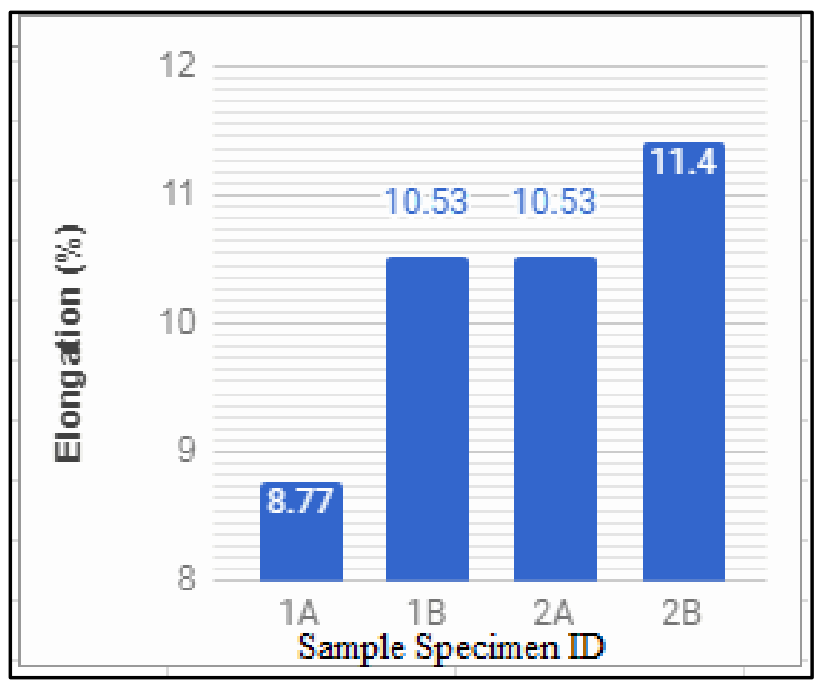

Fig 12: Elongation

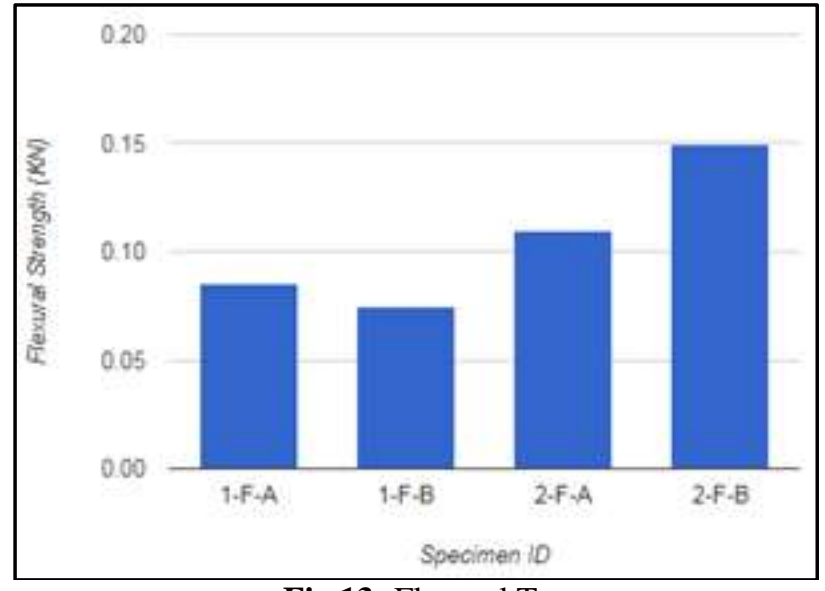

Fig 13: Flexural Test

\section{CONCLUSION}

In this study, tensile and flexural properties of kenaf and pineapple fabric reinforced composites were analysed and the pure kenaf composite exhibits better tensile strength results than that of the Pineapple/kenaf hybrid fabric reinforced composites. And the flexural strength of Pineapple/kenaf hybrid composites was exhibited better results than that of pure kenaf reinforced composites. The kenaf and pineapple fiber reinforced composites shown nature friendly characteristics. And more researches will be done in the future to enhance the manufacturing and processing of the fibers in a view to extend the scope of kenaf and pineapple fibers in the engineering field.

\section{REFERENCES}

[1] Onal, L. and Adanur, S. (2002), "Effect of Stacking Sequence on the Mechanical Properties of GlassCarbon Hybrid Composites before and after Impact", Journal of Industrial Textiles, 31, 255-271.

[2] M. Jacob, S. Thomas, K.T. Varughese, "Mechanical properties of sisal/oil palm hybrid fiber reinforced natural rubber composites", Composite Science and Technology. 64 (2004) 955-965.

[3] A. Satapathy, G. Kranthi, S. Mantry, and S.K. Singh, (2010), "Mechanical Characterization of Glass-Epoxy Hybrid Composites Reinforced with SiC Derived from Bamboo Leaves", Proceedings of Recent Advances in Fluid and Solid Mechanics, $27-$ 28.02, NIT Rourkela

[4] Sanjeevamurthy, G.C., Rangasrinivas, G. and Manu S. (2012)," Mechanical Performance of Natural Fiber-Reinforced Epoxy-Hybrid Composites", International Journal of Engineering Research and Applications (IJERA), 2, 615-619.

[5] Ramesh, M., Palanikumar, K. and Reddy, K.H. (2013), "Mechanical Property Evaluation of SisalJute-Glass Fiber Reinforced Polyester Composites", Composites: Part B, 48, 1-9. 
[6] Chaitanyan, C. and Raghuraman, S. (2013), "A Study of Mechanical Properties of Sisal-Glass Reinforced Hybrid Composites", IJARSET, 6, 1-6.

[7] Gujjala, R., Ojha, S., Acharya, S.K. and Pal, S.K. (2013), "Mechanical Properties of Woven JuteGlass Hybrid-Reinforced Epoxy Composite", Journal of Composite Materials.

[8] Alavudeen, A., Rajini, N., Karthikeyan, S., Thiruchitrambalam, M. and Venkateshwaren, N. (2015), "Mechanical Properties of Banana/Kenaf Fiber-Reinforced Hybrid Polyester Composites: Effect of Woven Fabric and Random Orientation", Materials and Design, 66, 246-257. 